\title{
ORIGINAL ARTICLE \\ Proton magnetic resonance spectroscopy and outcome in term neonates with chorioamnionitis
}

\author{
CB Johnson ${ }^{1,2}$, DD Jenkins ${ }^{3}$, JP Bentzley ${ }^{3}$, D Lambert ${ }^{3}, \mathrm{~K} \mathrm{Hope}^{3}$, LG Rollins ${ }^{4}$, PS Morgan ${ }^{5}, \mathrm{~T} \mathrm{Brown}^{1}, \mathrm{~V} \mathrm{Ramakrishnan}^{6}$, \\ DM Mulvihill ${ }^{3,7}$ and LD Katikaneni ${ }^{3}$
}

OBJECTIVE: Evaluate brain metabolites, which reflect neuroinflammation, and relate to neurodevelopmental outcomes in healthy term neonates exposed to chorioamnionitis.

STUDY DESIGN: Thirty-one healthy term neonates with documented fetal inflammatory response after maternal chorioamnionitis underwent magnetic resonance spectroscopy (MRS), with voxels placed in basal ganglia (BG) and frontal white matter. Bayley III examinations were performed at 12 months of age.

RESULT: Infants with below average outcomes did not show the same increase in NAA/Cho ratios postnatally as the group with normal outcomes. Decreased NAA/Cho and increased Lac/Cr in BG correlated with lower motor and cognitive composite scores, respectively, controlling for postnatal age. In males, increased lactate/NAA in BG were associated with lower motor scores. Funisitis severity was associated with decreased NAA/Cho and increased ml/NAA in males.

CONCLUSION: In healthy term newborns with chorioamnionitis, MRS ratios shortly after birth may provide evidence of occult neuroinflammation, which may be associated with worse performance on 1-year neurodevelopmental tests.

Journal of Perinatology (2015) 35, 1030-1036; doi:10.1038/jp.2015.121; published online 1 October 2015

\section{INTRODUCTION}

In chorioamnionitis, inflammation of the chorion and amnion membranes leads to significant secretion of inflammatory cytokines in the amniotic fluid. The resulting intra-amniotic inflammation may lead to a fetal inflammatory response that places infants at risk for adverse neurodevelopmental outcomes, regardless of gestational age. ${ }^{1-3}$ Neuroinflammation may proceed silently, and the ability to identify neonates with neuroinflammation who are at risk for developmental problems shortly after birth would help advance treatment options and allow monitoring and early treatment in this high-risk population. As chorioamnionitis is present in approximately $10 \%$ of all deliveries, this represents a significant population who may be at risk for developmental delay. ${ }^{4}$

Magnetic resonance spectroscopy (MRS) enables in vivo investigations of neural metabolic processes. By evaluating ratios of common metabolites, investigators have gained important mechanistic and prognostic information about disease processes such as hypoxia-ischemia, ${ }^{5}$ hydrocephalus, ${ }^{6}$ abnormal cardiac development ${ }^{7}$ and preterm chorioamnionitis. ${ }^{8}$ To date, there has been no MRS study of healthy term newborns with histological chorioamnionitis, although relative risk for subsequent cerebral palsy is 4.7 for near term and term infants exposed to chorioamnionitis. ${ }^{3,9}$ We hypothesized that the use of this neuroimaging modality in term neonates could detect inflammatory changes induced by chorioamnionitis, and that these metabolic ratios would be associated with 1-year neurodevelopmental outcome.

\begin{abstract}
METHODS
Study population

This study was approved by the Medical University of South Carolina's Institutional Review Board and was conducted between August 2006 and October 2011 on term infants born $\geq 37$ weeks gestation to mothers with chorioamnionitis, which we defined as clinical amniotic infection and maternal fever $>100.4{ }^{0} \mathrm{~F}$ in the presence of two of the following: uterine tenderness, maternal leukocytosis $>12000$ cells mm $\mathrm{mm}^{-1}$, fetal tachycardia $>160$ b.p.m. or maternal tachycardia $>100$ b.p.m. Exclusion criteria were the presence of any congenital abnormality or receiving therapeutic intervention in another trial. Mothers consented to participate in the study and have their infants' umbilical cords analyzed by a pathologist to confirm funisitis. Confirmed funisitis indicates a fetal systemic inflammatory response and makes noninfectious causes of intrapartum fever less likely. Infants with confirmed funisitis were scheduled for MRS scans as an outpatient between 1 and 4 weeks after discharge. The Bayley Scales of Infant Development III (Bayley) were used to evaluate infants' cognitive, language and motor skills at approximately 12 months of age. A single certified school psychologist performed all exams for this study.
\end{abstract}

\section{Umbilical cord/placental pathology}

All patients in the study had placental pathology performed to confirm funisitis. The umbilical cords were fixed in $10 \%$ neutral buffered formalin overnight. Three cross-sections of umbilical cord, from distal (fetal) and proximal (placental) ends and from the central (mid-) portion of the cord, were submitted for processing. Placental and umbilical cord histologic grading and staging was performed by a single pathologist according to criteria of Redline. ${ }^{10}$

\footnotetext{
${ }^{1}$ Department of Neuroscience's Center for Advanced Imaging Research, Medical University of South Carolina, Charleston, SC, USA; ${ }^{2}$ Department of Microbiology and Immunology, Medical University of South Carolina, Charleston, SC, USA; ${ }^{3}$ Department of Pediatrics, Medical University of South Carolina, Charleston, SC, USA; ${ }^{4}$ Department of Clinical Psychology, University of Massachusetts, Boston, MA, USA; ${ }^{5}$ Department of Medical Physics, Nottingham University Hospitals NHS Trust, Nottingham, UK; ${ }^{6}$ Department of Biostatistics and Epidemiology, Medical University of South Carolina, Charleston, SC, USA and ${ }^{7}$ Department of Radiology, Medical University of South Carolina, Charleston, SC, USA. Correspondence: Dr LD Katikaneni, Department of Pediatrics, Medical University of South Carolina, 165 Ashley Avenue, MSC 917, Charleston, SC 29425, USA. 

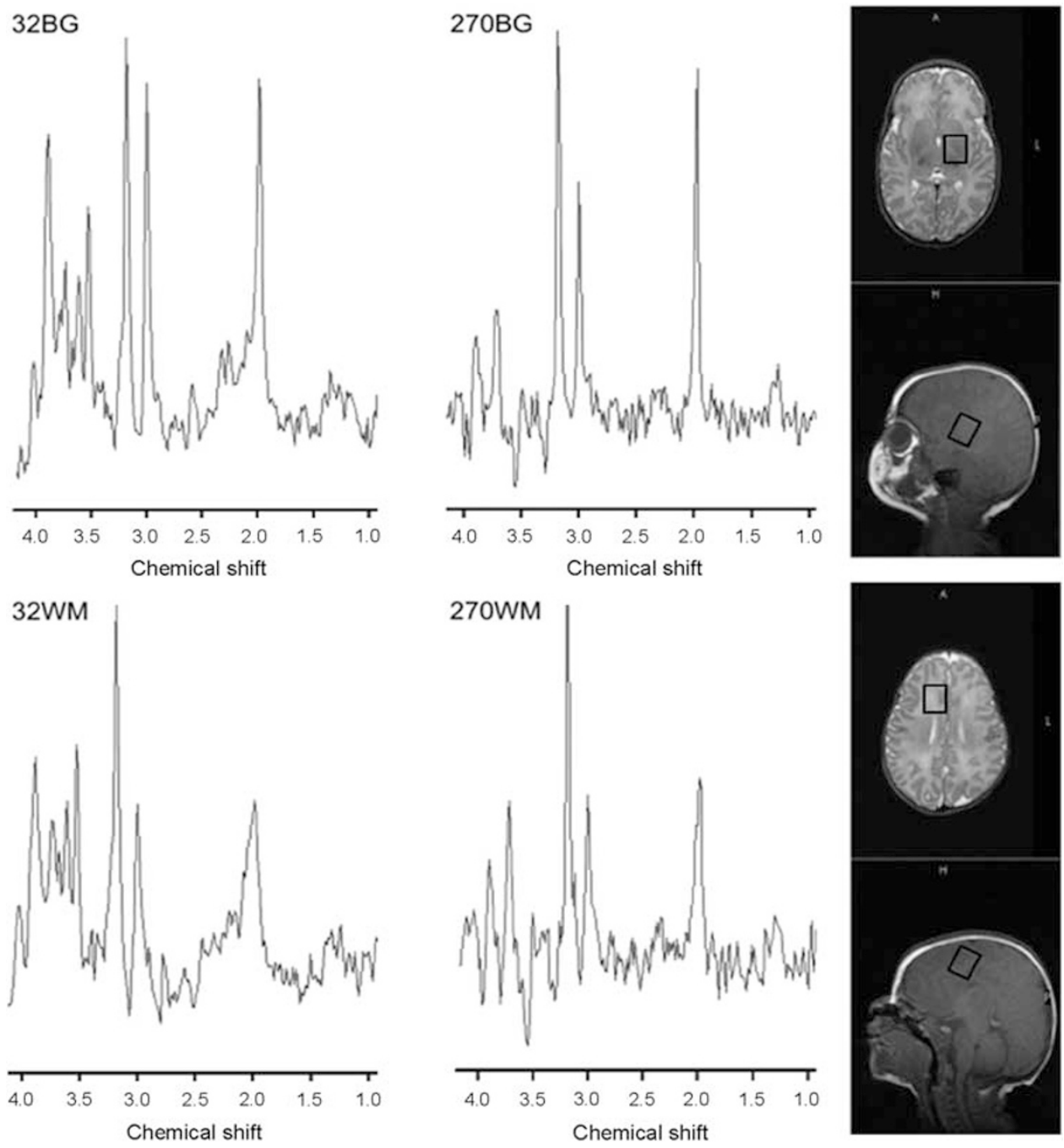

Figure 1. Magnetic resonance (MR) images showing voxel placements in the basal ganglia (BG, top) and frontal white matter (WM, bottom) and representative spectra at echo times of 32 (left) and 270 (right) ms.

\section{Magnetic resonance spectroscopy}

MRS was obtained shortly after birth using a Philips or Siemens 3 T system (Intera, Philips Medical, Best, The Netherlands; or Trio, Siemens Medical, Erlangen, Germany). Scans were obtained using a standard adult head coil. Owing to time constraints, limited T1 axial and T2 sagittal images were obtained for voxel localization. Diffusion tensor imaging along with spectroscopy data were acquired at the same session on unsedated infants. Diffusion tensor imaging data are not reported here. Single-voxel $1 \mathrm{H}-\mathrm{MR}$ spectra using point-resolved spectroscopy were acquired with both short (32 ms Philips; $30 \mathrm{~ms}$ Siemens) and long $(270 \mathrm{~ms})$ echo times (TE), a relaxation time of $1.5 \mathrm{~s}$ and signal averages of 128 . A single-voxel size of $15 \times 15 \times 15 \mathrm{~mm}$ was used for measurements in the basal ganglia (BG) and in the frontal lobe white matter (WM; Figure 1). Spectra were fit using LCModel with standard Philips or Siemens basis sets. ${ }^{11}$ The concentration of metabolites myo-inositol $(\mathrm{ml})$, total choline ${ }^{12}$ and total creatine ${ }^{13}$ were measured at short TE, whereas lactate, ${ }^{14} \mathrm{~N}$-acetyl-aspartate and $\mathrm{N}$ acetylaspartylglutamate (NAA), Cho and $\mathrm{Cr}$, at long TE. Lac/NAA, $\mathrm{Lac} / \mathrm{Cr}$, $\mathrm{NAA} / \mathrm{Cho}, \mathrm{NAA} / \mathrm{Cr}, \mathrm{ml} / \mathrm{NAA}, \mathrm{ml} / \mathrm{Cho}$ and $\mathrm{ml} / \mathrm{Cr}$ concentration ratios were used for analysis. Spectra from each manufacturer's scanner were analyzed separately and then concentration ratios compared between scanners. For metabolites at $270 \mathrm{~ms} \mathrm{TE}$, there were no differences in concentration ratios by scanner, and therefore data at $\mathrm{TE}=270 \mathrm{~ms}$ were combined for patients scanned on both the Philips and Siemens machines. However, $\mathrm{ml}$ ratios, which are best detected at $\mathrm{TE}=32 \mathrm{~ms}$, were only analyzed in the subsample scanned on the Philips machine because of incoherence of data from two different scanners and on the recommendation of our MRS expert (T Brown, PhD). All metabolites had s.d. $\leq 20 \%$ of the concentration by Cramer Rao as the standard for inclusion with the exception of Lac, which was assessed individually.

\section{Statistical analysis}

Sample size is estimated based on a power analysis that was performed using a general linear model with three factors. The sample size requirement of 25 patients is estimated to provide an $80 \%$ power (Cohen's effect size of 0.20 ) to detect a $20 \%$ predictive variable difference. To account for a dropout rate of about $50 \%$, we aimed to enroll approximately 50 patients for this study. To assess the homogeneity of variance within the study sample, Fisher's exact test and Pearson's chi-square were used for dichotomously scaled variables and Student's $t$-test was used for continuous variables. Pearson's correlation coefficient was used to determine the effects of time from birth to scan or postnatal age (PNA), and postconceptional gestational age at scan on MRS metabolite ratios. A general linear model was used to explore the relationship between MRS metabolite ratios and Bayley composite domain scores, controlling for the effect of PNA and gender on MRS metabolite ratios. We report adjusted $r^{2}$ values $\left(r^{2}\right.$, general linear model) for each significant association. To better define gender effects, semipartial correlations ( $r$ in single gender analyses, semipartial correlation coefficient) were calculated within each gender for Bayley scores and MRS ratios, controlling for the effect of PNA. For all statistical tests, the level of significance was set with $P<0.05$ and the confidence interval of $95 \%$. With the small sample size in these exploratory 


\begin{tabular}{|c|c|c|c|}
\hline & $\begin{array}{l}\text { Females, } \\
\mathrm{n}=19\end{array}$ & $\begin{array}{l}\text { Males, } \\
\mathrm{n}=24\end{array}$ & $\begin{array}{l}\text { Total, } \\
\mathrm{n}=43\end{array}$ \\
\hline \multicolumn{4}{|l|}{ Ethnic group } \\
\hline Latino & 9 & 13 & 22 \\
\hline African-American & 7 & 10 & 17 \\
\hline Caucasian & 2 & 1 & 3 \\
\hline Other & 1 & 0 & 1 \\
\hline \multicolumn{4}{|l|}{ Entry strata } \\
\hline $\begin{array}{l}\text { Gestational age at birth } \\
\text { (week, mean } \pm \text { s.d.) }\end{array}$ & $39.5 \pm 1.3$ & $39.5 \pm 1.2$ & $39.5 \pm 1.3$ \\
\hline Birth weight $(g$, mean \pm s.d.) & $3449 \pm 413$ & $3407 \pm 483$ & $3425 \pm 449$ \\
\hline \multicolumn{4}{|l|}{ Clinical status } \\
\hline $\begin{array}{l}\text { Length of maternal fever } \\
\text { (hour, median and IQR) }\end{array}$ & $3(2-6)$ & $2(2-3)$ & $2(2-6)$ \\
\hline Cesarean-section delivery & $7(37 \%)$ & $10(42 \%)$ & $17(40 \%)$ \\
\hline Apgar @ 1 min (median and IQR) & $8(4-8)$ & $8(6-9)$ & $8(5-8)$ \\
\hline Apgar @ 5 min (median and IQR) & $9(8-9)$ & $9(9-9)$ & $9(8-9)$ \\
\hline \multicolumn{4}{|l|}{ Cord stage } \\
\hline Mild & 7 (37\%) & $10(42 \%)$ & $17(40 \%)$ \\
\hline Moderate/severe & $12(63 \%)$ & $14(58 \%)$ & $26(60 \%)$ \\
\hline \multicolumn{4}{|l|}{ Cord grade } \\
\hline Mild & $12(63 \%)$ & $15(63 \%)$ & 27 (63\%) \\
\hline Moderate/severe & $7(37 \%)$ & $9(67 \%)$ & $16(37 \%)$ \\
\hline $\begin{array}{l}\text { Length of hospital stay } \\
\text { (days, median and IQR) }\end{array}$ & $3(2-4)$ & $2(2-3)$ & $2(2-4)$ \\
\hline
\end{tabular}

analyses, we did not correct for multiple comparisons, but note when correction for multiple comparison testing of seven metabolite ratios would still yield significant results. Final statistics were obtained using SPSS 17.0 (SPSS Inc., Chicago, IL, USA).

\section{RESULTS}

\section{Demographic data}

Of the 71 term infants approached for participation in this study, 55 participants were consented and had umbilical cord histology. Of these, two umbilical cords were lost and nine had no evidence of cord inflammation. A total of $17 \%(9 / 53)$ of consented mothers with clinical evidence of chorioamnionitis had negative cord histology. Therefore, 44 participants had confirmed funisitis. There were no significant differences in infant demographic data (Table 1)

No infant had positive blood cultures. Most infants $(n=33)$ were treated in the level I nursery and discharged home within 2 to 3 days, per routine after blood cultures were negative. Based upon complete blood count abnormalities ten patients were admitted to the level II nursery for suspected sepsis and received between 3 and 7 days of antibiotics. None of these level II infants had hypotension, shock or respiratory distress. Two infants received saline in the delivery room for delayed transition with capillary refill of $>3 \mathrm{~s}$ with normal heart rates and blood pressures. They underwent a sepsis evaluation, but had no other resuscitative interventions. Neurologic status was normal in these patients. One male infant was admitted to the level III nursery for treatment of seizures because of presumed hypoxic-ischemic encephalopathy with a cord $\mathrm{pH}$ of 6.98 . Although this infant represents the spectrum of chorioamnionitis, which is frequently complicated by hypoxic-ischemic encephalopathy, we excluded him from the reported analyses, as he was atypical of the other healthy newborns.

Of the 43 infants who had funisitis (omitting the hypoxicischemic encephalopathy infant), 39 returned for the scan during the required time, between 0.2 and 4.0 weeks after birth (mean $1.5 \pm 0.9$ weeks, postconceptional gestational age 38 to 44 weeks).

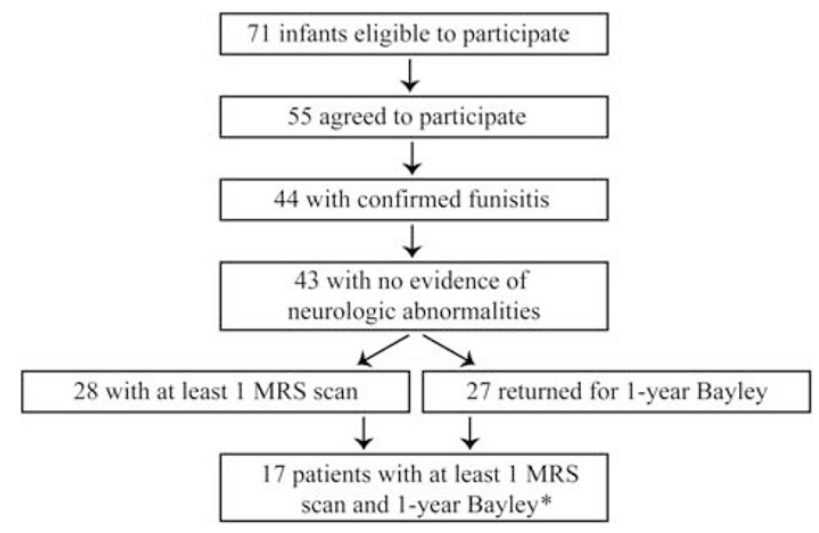

Figure 2. Diagram depicting patient enrollment and follow-up. * Final range is 13 to 17 because not all metabolites from each of the four scans (two echo times in two brain areas) met magnetic resonance spectroscopy (MRS) quality criteria.

Eight patients' raw MRS data could not be retrieved. All scans were for research only, and included limited T1 and T2 images, which were normal, without overt gray matter or WM injury. Of the remaining 31 patients, 3 did not have any scans that met quality inclusion criteria. We report on 28 and 27 infants for NAA and choline ratios in the BG and WM, respectively, and 27 and 26 infants for Lac ratios in the BG and WM, respectively. For $\mathrm{ml}$, we had 21 usable scans in the WM, 15 in the BG for $\mathrm{ml} /$ Cho and $\mathrm{ml} / \mathrm{Cr}$, and 14 in the BG for ml/NAA.

Twenty-seven infants were seen for 1-year neurodevelopmental follow-up between the ages of 11.0 and 13.2 months, with a mean of 11.9 months (Figure 2). We dichotomized outcomes by Bayley domains. Infants who scored $\leq 8$ in at least one scaled Bayley domain were categorized as 'low/below average' and those who scored $>8$ in all scaled Bayley domains were categorized as 'average.' Low/below average gross motor scores were present in eight infants (four males, four females), and low/below average expressive language scores were present in four males. Neurodevelopment scores did not differ by sex for dichotomized outcome scores.

Infants with low versus average outcome scores have different NAA maturation patterns

Metabolite ratios are known to change after birth in the neonate as part of normal development. ${ }^{15}$ We analyzed the relationship between PNA (or time from birth to scan) and postconceptional gestational age at scan, and found they were significantly correlated in our sample $(r=0.497, P=0.001)$, and not independent. Therefore, we analyzed which parameter of maturation was more discriminatory for MRS ratio differences. If significant neuroinflammation is present after exposure to chorioamnionitis, then brain metabolites may reflect this injury at the time of birth. The normal maturation pattern would then be altered. Compared with infants without significant neuroinflammation, slower postnatal maturation of MRS metabolites would occur in these infants, regardless of conceptional age. ${ }^{16}$

In our infants with average Bayley scores at 1 year of age, we did observe the normal pattern of increased NAA/Cho or NAA/Cr with increasing PNA (Figure 3a). However, in those patients with below/low average Bayley scores in any domain, NAA ratios were not associated with PNA, indicating a different NAA trajectory in those infants exposed to chorioamnionitis who subsequently have poorer outcome scores. In contrast, NAA ratios were related to conceptional age to a similar degree in infants with average and below average scores (Figure $3 \mathrm{~b}$ ). Therefore, PNA distinguished 

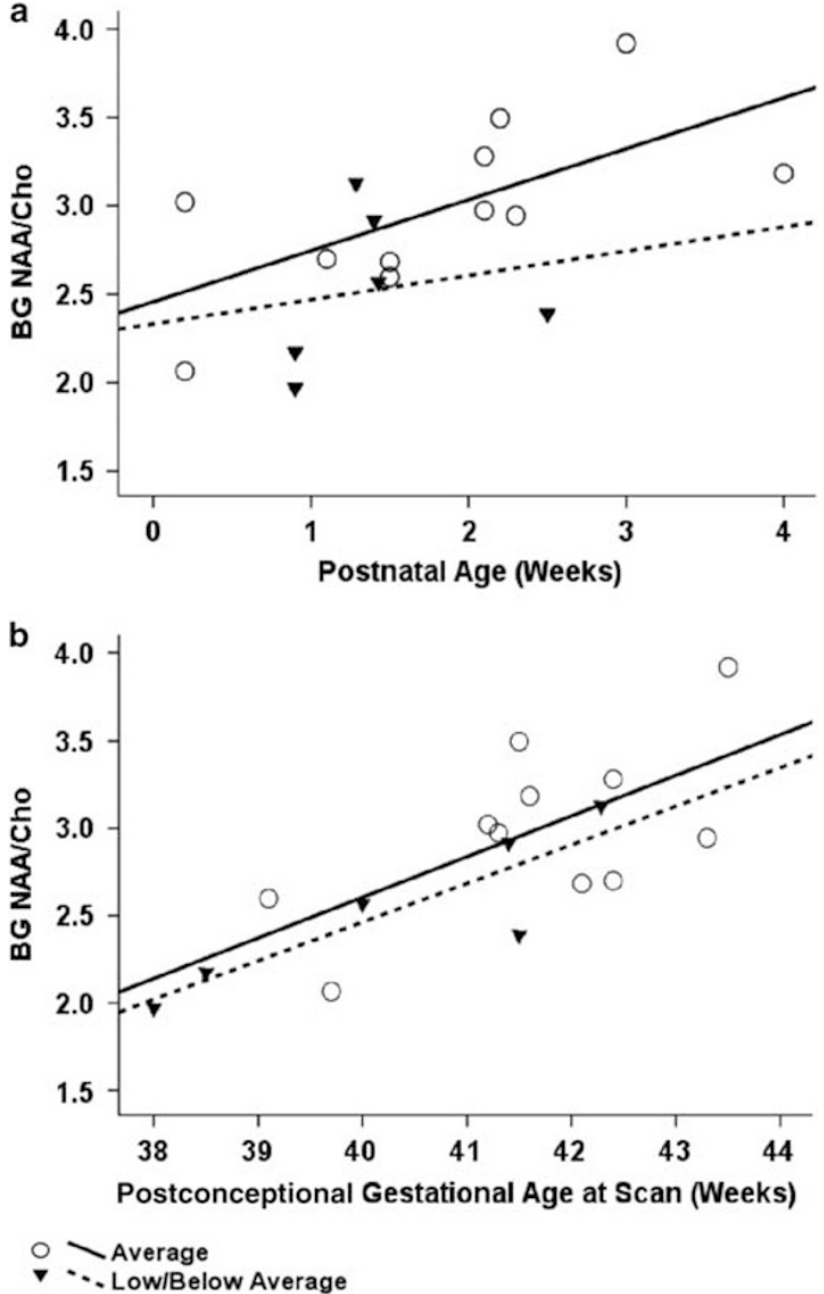

Figure 3. Plots demonstrating regressions of NAA/Cho in the basal ganglia (BG) between infants with average versus low/below average Bayley III outcome scores in the combined sex group. (a) Infants with average Bayley III scores at 1 year had significant changes over postnatal age (PNA; time from birth to scan) in NAA/ Cho in BG $(r=+0.658, P=0.028)$. However, in infants with low or below average Bayley scores, there were no significant changes over PNA for NAA/Cho in BG $(r=+0.183, P=0.729)$. (b) Both outcome groups exhibited significant changes over postconceptional gestational age at scan (PCA) in NAA/Cho in BG; average outcome group: $r=+0.635, \quad P=0.036$ and low/below average group: $r=+0.876, P=0.022$.

the altered maturation pattern of NAA metabolites in term infants with worse outcomes after exposure to chorioamnionitis, providing indirect evidence of neuroinflammatory injury at birth.

The severity of fetal inflammatory response is associated with MRS metabolites in male infants

Infant umbilical and maternal placental stages and grades of inflammation were significantly associated with one another, $P=0.007$ and $P=0.001$, respectively. Males and females had similar degrees of funisitis $(P \geq 0.9)$. Compared with males with mild funisitis, males with more severe funisitis (grade 2 ) had significantly lower NAA/Cho in the BG $(n=10$ for mild funisitis, $n=5$ for more severe funisitis; $P=0.001$ ) and higher $\mathrm{ml} / \mathrm{NAA}$ in the WM (mild $n=9$, more severe $n=5, P=0.018$ ) ratios. There was no significant effect of funisitis grade or stage on MRS metabolite ratios in females or the combined sex group. Importantly, the

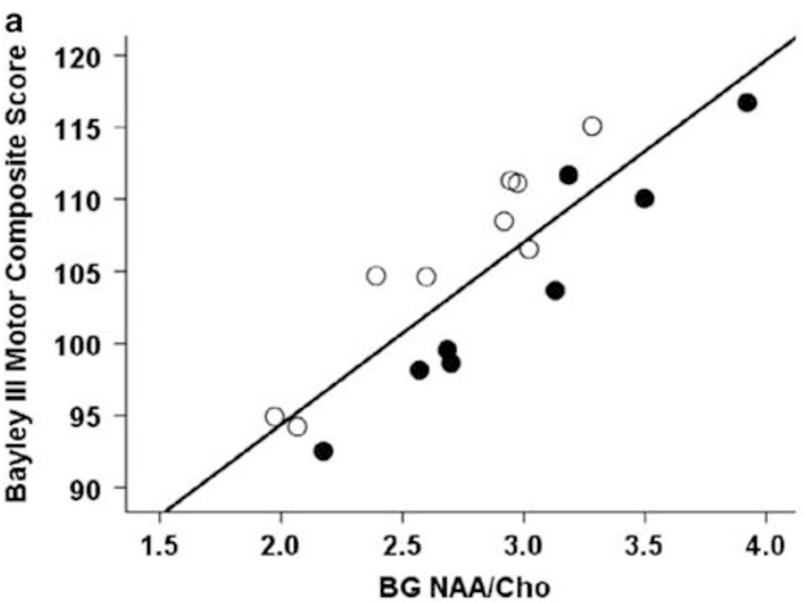

1033

b

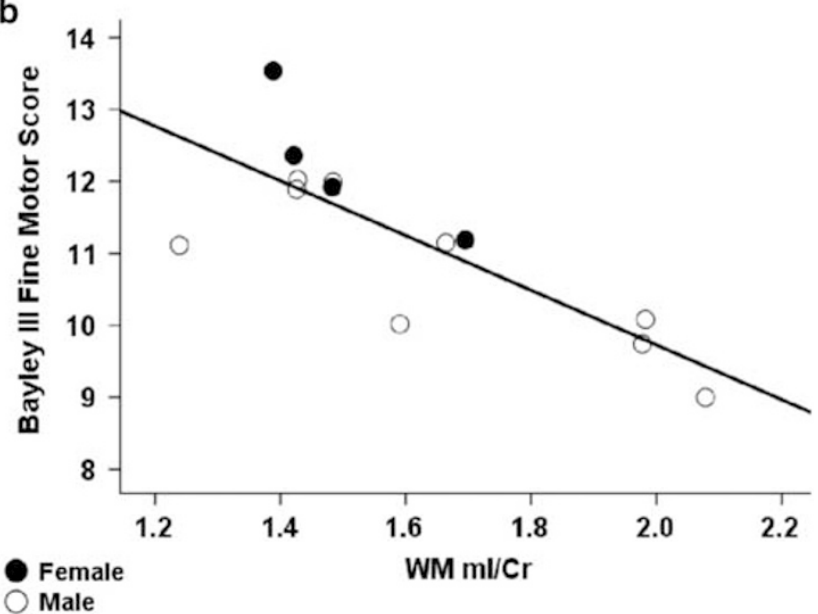

Figure 4. Regression plots of magnetic resonance spectroscopy (MRS) metabolite ratios compared with 12-month Bayley III motor scores controlling for gender and postnatal age (PNA). (a) NAA/Cho in basal ganglia (BG) compared with motor composite scores; (b) $\mathrm{ml} / \mathrm{Cr}$ ratios in white matter (WM) compared with fine motor domain scores. Data points represent individual patients.

severity of funisitis did not have an effect on outcome independent of the effect on MRS ratios, a finding that highlights the importance of the fetal neuroinflammatory response in neurodevelopmental outcome after chorioamnionitis.

MRS metabolite ratios correlate to motor development

$\mathrm{NAA} / \mathrm{Cho}$ in the BG correlated positively with motor composite scores (Figure 4a). In the WM, $\mathrm{ml} / \mathrm{Cr}$ was negatively associated with fine motor scores (Figure $4 \mathrm{~b}$ ). Cho/ $\mathrm{Cr}$ ratios in the BG and WM were negatively associated with motor composite scores. These changes are similar to the MRS changes in term infants with hypoxic ischemic injury in whom NAA ratios correlated positively with motor composite scores, whereas lactate and $\mathrm{ml}$ ratios correlated negatively. ${ }^{5}$

Although sex did not have a significant effect on MRS metabolite ratios overall, sex was a significant factor in the model for association of lactate ratios with gross and fine motor scores, controlling for PNA (Figure 5). In females, lactate ratios in WM were negatively associated with fine motor scores $(n=8$, Lac/NAA: $r=-0.745, P=0.043$, Figure 5b; Lac/Cr: $r=-0.424, P=0.038)$. In males, Lac/NAA ratio in the BG had a strong association with gross 
motor scores and motor composite at 12 months ( $n=9$, Lac/NAA and gross motor: $r=-0.856, P=0.007$, Figure $5 \mathrm{a}$; $\mathrm{Lac} / \mathrm{Cr}$ and gross motor: $r=-0.799, P=0.031$; Lac/NAA and motor composite: $r=-0.755, \quad P=0.024)$. Lac/NAA ratios remain significantly
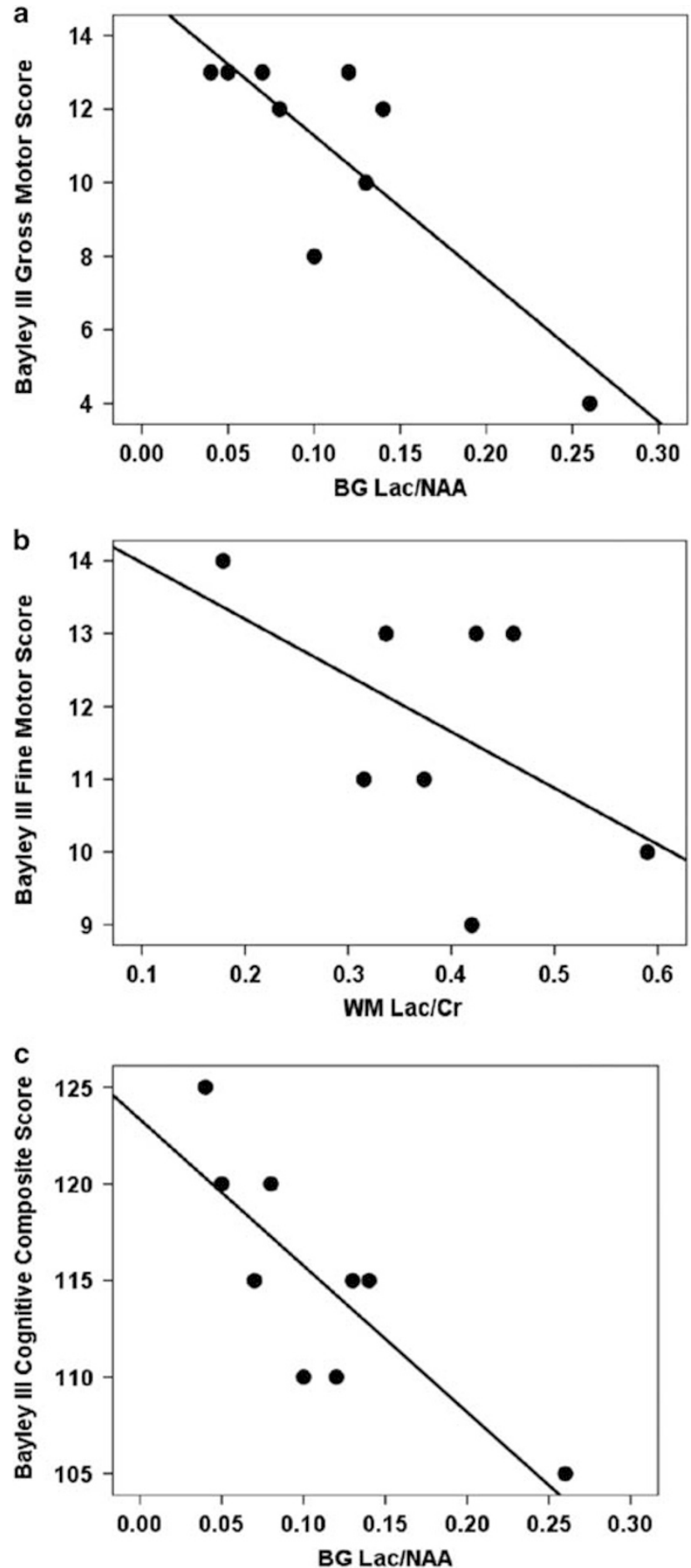

Figure 5. Regression plots of $\mathrm{Lac} / \mathrm{Cr}$ metabolite ratios compared with 12-month Bayley III scores. (a) In males, Lac/Cr ratios in basal ganglia (BG) correlate significantly with gross motor domain scores. (b) In females, $\mathrm{Lac} / \mathrm{Cr}$ ratios in white matter (WM) correlate significantly with fine motor domain scores. (c) In males, $\mathrm{Lac} / \mathrm{Cr}$ in BG correlate significantly with cognitive composite scores. Data points represent raw data on individual patients. negatively associated with gross motor scores in males, even after correction for multiple comparisons testing of seven metabolite ratios. Lac/NAA ratios in the BG combine two strong indicators of neuroinflammation and maturation, and have been shown to be among the best predictors of 18-month outcome after neuroinflammation because of hypoxic ischemic injury. ${ }^{17}$ In our cohort exposed to chorioamnionitis, Lac/NAA ratios in the BG are also strongly associated with motor outcomes, but reflect the interaction of neuroinflammation because of chorioamnionitis and male sex on motor outcomes.

Cognitive and language development correlate with MRS metabolite ratios

Lactate ratios in the BG were also negatively associated with cognitive composite scores in the mixed model, which controls for gender and PNA (Table 2). Lac/NAA and $\mathrm{Lac} / \mathrm{Cr}$ in BG were negatively associated with cognitive composite scores in males $(n=9$; Lac/NAA: $r=-0.784, P=0.016$, Figure 5c; Lac/Cr: $r=-0.771$, $P=0.034)$. WM $\mathrm{ml} / \mathrm{Cr}$ was negatively associated with expressive language scores (Table 2), with a significant gender effect and an interaction effect between gender and $\mathrm{ml} / \mathrm{Cr}$ interaction ( $P=0.003$, significant after multiple comparisons correction). Other exploratory analyses are presented in Table 2.

\section{DISCUSSION}

In this study, we report the correlation of brain metabolites to 1-year neurodevelopmental outcome in term babies with histological chorioamnionitis with confirmed fetal inflammatory response. The relationship between chorioamnionitis and neurodevelopmental outcome is supported by experimental evidence in animal models, epidemiologic studies, and two meta-analyses that identified chorioamnionitis as a risk factor for cerebral palsy. ${ }^{1,3,18}$ However, conflicting findings have also been reported. Histologic chorioamnionitis was not associated with adverse long-term outcomes in preterm infants, ${ }^{14}$ or with IQ tests at 3.5 or 7 years of age in term infants, ${ }^{13}$ perhaps because of heterogeneity of etiologies of chorioamnionitis. Recent studies have shown that chorioamnionitis at term may be noninfectious. ${ }^{19,20}$ In our cohort of healthy term babies diagnosed with chorioamnionitis, only those with documented funisitis were included to ensure as much as possible that chorioamnionitis was due to infectious etiologies.

The pathogenesis of chorioamnionitis-mediated neuroinflammation is thought to be a result of bacterial engagement of Toll-like receptors on innate immune cells. ${ }^{21}$ This elicits an increase in amniotic cytokines, with interleukin-1 having a crucial role, ${ }^{22}$ followed by increased fetal/neonatal plasma levels of inflammatory mediators such as interleukin- $6 .{ }^{23}$ These cytokines lead to cerebral damage in some patients by activating microglia, leading to neuroinflammation and subsequent disruptions in neuronal developmental. ${ }^{24}$ The individual's response to chorioamnionitis may depend on factors including genetics, epigenetics, environmental factors and sex.

A recent study demonstrated that males have increased responsiveness to lipopolysaccharide, a Toll-like receptor-4 agonist. ${ }^{25}$ This response concurs with our findings that the severity of funisitis in male infants was associated with significant changes in MRS metabolites, indicating an interplay between male sex, systemic and neuroinflammatory responses. Lactate and NAA metabolites in BG independently correlate with motor outcome in males. However, the grade or stage of funisitis was not itself directly associated with outcome in either gender, suggesting that the presence of a fetal neuroinflammatory response, as indicated by Lac/NAA for example, may be more important for neurodevelopment than the severity of the cord inflammation itself.

In normally developing infants, NAA increases rapidly near term $\mathrm{GA}$, reflecting neuronal activity and maturation, ${ }^{26}$ and the in utero 


\begin{tabular}{|c|c|c|c|c|c|c|}
\hline BG & NAA/Cho & Motor composite & Positive & 0.388 & 0.032 & 17 \\
\hline BG & $\mathrm{Cho} / \mathrm{Cr}$ & Fine motor & Negative & 0.263 & 0.039 & 15 \\
\hline BG & $\mathrm{Lac} / \mathrm{Cr}$ & Cognitive composite & Negative & 0.375 & 0.057 & 17 \\
\hline WM & $\mathrm{ml} / \mathrm{Cr}$ & Expressive language & Negative & 0.618 & 0.023 & 13 \\
\hline
\end{tabular}

rate of incorporation of NAA is identical to the postnatal rate of accumulation. ${ }^{15,27}$ In the presence of an inflammatory insult, such as chorioamnionitis, this normal maturation may be altered at specific time points. As chorioamnionitis is typically a perinatal insult, it may impair NAA accumulation in neurons beginning at birth. If so, a decrease in NAA would be better reflected by the postnatal age than postconceptional age at time of scan, as we found in our healthy term newborns. Thus, our data suggest that MRS metabolites may reflect occult neuroinflammation, which starts at birth after exposure to chorioamnionitis. Other reports indicate that early alterations in expected NAA maturation after birth may have long-term neurodevelopmental consequences. ${ }^{12}$ In our population of neonates with pathologically verified funisitis and fetal systemic inflammatory response because of chorioamnionitis, infants with lower NAA ratios in the BG also scored below normal on the 1-year Bayley exam. Elevated lactate ratios are associated with worse outcome scores, reflecting an imbalance in neuroenergetics secondary to inflammation. High levels of lactate have been correlated to elevated interleukin-1 and interleukin-6.22,23,28 These cytokines can activate astrocytes to increase their glucose uptake as a means to increase glutathione levels and dampen oxidative stress. ${ }^{29}$ If host inflammation is left unchecked, lactate may continue to accumulate in the astrocyte, thereby reducing astrocyte-mediated protection of neurons. ${ }^{30}$ These changes in neuroenergetics could have an impact on synaptogenesis and myelination, which in turn may lead to impaired motor function or memory and learning. ${ }^{31}$

Acute neuroinflammatory conditions have also been shown to lead to glial accumulation of $\mathrm{ml}$ on $\mathrm{MRS}^{32,33}$ an important component of the phosphatidylinositol 3-kinase signaling pathway and a marker of activated astrocytes and microglia. ${ }^{34-36}$ In our cohort, increased $\mathrm{ml}$ ratios in the WM were associated with poorer outcomes. Thus, the elevation of this metabolite suggests an ongoing inflammatory response, as well as possible astrogliosis at the site of injury. ${ }^{37}$

Limitations of our study include the small number of femalemale participants in some categories and the lack of non-exposed infants as a control group. We expected many of our infants to have normal development, and our comparisons were aimed at determining which brain metabolites could distinguish between those with normal and below normal development after exposure to chorioamnionitis. In clinical practice, MRS will likely be more restricted to at-risk populations, and we wished to study the utility of this neuroimaging modality in a clinically relevant scenario. ${ }^{6,26}$

Our 12-month developmental results will need to be confirmed with longer follow-up and greater numbers in term infants. However, our study provides evidence that abnormalities in brain metabolism can be detected in healthy term infants with funisitis, and correlate with intermediate term outcomes. Clinical factors and cord/placental inflammatory grade failed to identify these individuals at risk for delay, but MRS metabolite ratios obtained within a few weeks after birth were associated with 1-year outcome scores. If our results are confirmed in other studies, MRS may be a useful screening test to identify term infants at higher risk of developmental problems after exposure to chorioamnionitis.

In conclusion, funisitis and the ensuing host response to inflammation are correlated with MRS metabolites shortly after birth, and the degree of effect on metabolites is related to neurodevelopmental outcome scores at 12 months.

\section{CONFLICT OF INTEREST}

The authors declare no conflict of interest.

\section{ACKNOWLEDGEMENTS}

This study was supported by a grant from March of Dimes (grant\# 12-FY06-239) and by 5 F30CA177208.

\section{REFERENCES}

1 Shatrov JG, Birch SC, Lam LT, Quinlivan JA, Mclntyre S, Mendz GL. Chorioamnionitis and cerebral palsy: a meta-analysis. Obstet Gynecol 2010; 116(2 Pt 1): 387-392.

2 Mittendorf R, Montag AG, MacMillan W, Janeczek S, Pryde PG, Besinger RE et al. Components of the systemic fetal inflammatory response syndrome as predictors of impaired neurologic outcomes in children. Am J Obstet Gynecol 2003; 188(6): 1438-1434; discussion 1444-1436.

$3 \mathrm{Wu}$ YW, Colford JM Jr. Chorioamnionitis as a risk factor for cerebral palsy: a meta-analysis. JAMA 2000; 284(11): 1417-1424.

4 Soper DE, Mayhall CG, Dalton HP. Risk factors for intraamniotic infection: a prospective epidemiologic study. Am J Obstet Gynecol 1989; 161(3): 562-566; discussion 566-568.

5 Barkovich AJ, Baranski K, Vigneron D, Partridge JC, Hallam DK, Hajnal BL et al. Proton MR spectroscopy for the evaluation of brain injury in asphyxiated, term neonates. Am J Neuroradiol 1999; 20(8): 1399-1405.

6 McNatt SA, McComb JG, Nelson MD, Bluml S. Proton magnetic resonance spectroscopy of hydrocephalic infants. Pediatr Neurosurg 2007; 43(6): 461-467.

7 Miller SP, McQuillen PS, Hamrick S, Xu D, Glidden DV, Charlton N et al. Abnormal brain development in newborns with congenital heart disease. N Engl J Med 2007; 357(19): 1928-1938.

8 Chau V, Poskitt KJ, McFadden DE, Bowen-Roberts T, Synnes A, Brant R et al. Effect of chorioamnionitis on brain development and injury in premature newborns. Ann Neurol 2009; 66(2): 155-164.

9 Wu YW, Escobar GJ, Grether JK, Croen LA, Greene JD, Newman TB. Chorioamnionitis and cerebral palsy in term and near-term infants. JAMA 2003; 290 (20): 2677-2684

10 Redline RW, Faye-Petersen O, Heller D, Qureshi F, Savell V, Vogler C. Amniotic infection syndrome: nosology and reproducibility of placental reaction patterns. Pediatr Dev Pathol 2003; 6(5): 435-448.

11 Provencher SW. Estimation of metabolite concentrations from localized in vivo proton NMR spectra. Magn Reson Med 1993; 30(6): 672-679.

12 Boichot C, Walker PM, Durand C, Grimaldi M, Chapuis S, Gouyon JB et al. Term neonate prognoses after perinatal asphyxia: contributions of MR imaging, MR spectroscopy, relaxation times, and apparent diffusion coefficients. Radiology 2006; 239(3): 839-848.

13 Becroft DM, Thompson JM, Mitchell EA. Placental chorioamnionitis at term: epidemiology and follow-up in childhood. Pediatr Dev Pathol 2010; 13(4): 282-290.

14 Hendson L, Russell L, Robertson CM, Liang Y, Chen Y, Abdalla A et al. Neonatal and neurodevelopmental outcomes of very low birth weight infants with histologic chorioamnionitis. J Pediatr 2011; 158(3): 397-402.

15 Kreis R, Hofmann L, Kuhlmann B, Boesch C, Bossi E, Huppi PS. Brain metabolite composition during early human brain development as measured by quantitative 
in vivo $1 \mathrm{H}$ magnetic resonance spectroscopy. Magn Reson Med 2002; 48(6): 949-958.

16 Robertson NJ, Kuint J, Counsell TJ, Rutherford TA, Coutts A, Cox IJ et al. Characterization of cerebral white matter damage in preterm infants using $1 \mathrm{H}$ and $31 \mathrm{P}$ magnetic resonance spectroscopy. J Cereb Blood Flow Metab 2000; 20(10): 1446-1456.

17 Thayyil S, Chandrasekaran M, Taylor A, Bainbridge A, Cady EB, Chong WK et al. Cerebral magnetic resonance biomarkers in neonatal encephalopathy: a meta-analysis. Pediatrics 2010; 125(2): e382-e395.

18 Redline RW, O'Riordan MA. Placental lesions associated with cerebral palsy and neurologic impairment following term birth. Arch Pathol Lab Med 2000; 124(12): 1785-1791.

19 Riley LE, Celi AC, Onderdonk AB, Roberts DJ, Johnson LC, Tsen LC et al. Association of epidural-related fever and noninfectious inflammation in term labor. Obstet Gynecol 2011; 117(3): 588-595.

20 Roberts DJ, Celi AC, Riley LE, Onderdonk AB, Boyd TK, Johnson LC et al. Acute histologic chorioamnionitis at term: nearly always noninfectious. PLoS One 2012; 7 (3): e31819.

21 McAdams RM, Juul SE. The role of cytokines and inflammatory cells in perinatal brain injury. Neurol Res Internat 2012; ; 2012: 561494.

22 Kallapur SG, Nitsos I, Moss TJ, Polglase GR, Pillow JJ, Cheah FC et al. IL-1 mediates pulmonary and systemic inflammatory responses to chorioamnionitis induced by lipopolysaccharide. AM J Resp Crit Care 2009; 179(10): 955-961.

23 Pacora P, Chaiworapongsa T, Maymon E, Kim YM, Gomez R, Yoon BH et al. Funisitis and chorionic vasculitis: the histological counterpart of the fetal inflammatory response syndrome. J Matern Fetal Neonatal Med 2002; 11(1): 18-25.

24 Malaeb S, Dammann O. Fetal inflammatory response and brain injury in the preterm newborn. J Child Neurol 2009; 24(9): 1119-1126.

25 Kim-Fine S, Regnault TR, Lee JS, Gimbel SA, Greenspoon JA, Fairbairn J et al. Male gender promotes an increased inflammatory response to lipopolysaccharide in umbilical vein blood. J Matern Fetal Neonatal Med 2012; 25(11): 2470-2474.

26 Xu D, Bonifacio SL, Charlton NN, Vaughan CP, Lu Y, Ferriero DM et al. MR spectroscopy of normative premature newborns. J Magn Reson Imaging 2011; 33(2): 306-311.

27 Dezortova M, Hajek M. (1)H MR spectroscopy in pediatrics. Eur J Radio/ 2008; 67 (2): $240-249$.
28 Turner MA, Drury JA, Carlin A, O'Neill S, Pilling D, Barnes N et al. CSF cytokine levels in preterm infants may reflect systemic inflammation and are independent of gestation. Early Hum Dev 2009; 85(4): 259-262.

29 Belanger M, Magistretti PJ. The role of astroglia in neuroprotection. Dialogues Clin Neurosci 2009; 11(3): 281-295.

30 Liao SL, Chen CJ. L-glutamate decreases glucose utilization by rat cortical astrocytes. Neurosci Lett 2003; 348(2): 81-84.

31 Suzuki A, Stern SA, Bozdagi O, Huntley GW, Walker RH, Magistretti PJ et al. Astrocyte-neuron lactate transport is required for long-term memory formation. Cell 2011; 144(5): 810-823.

32 Bitsch A, Bruhn $H$, Vougioukas V, Stringaris A, Lassmann $H$, Frahm J et al. Inflammatory CNS demyelination: histopathologic correlation with in vivo quantitative proton MR spectroscopy. Am J Neuroradiol 1999; 20(9): 1619-1627.

33 Mader I, Rauer S, Gall P, Klose U. (1)H MR spectroscopy of inflammation, infection and ischemia of the brain. Eur J Radiol 2008; 67(2): 250-257.

34 Brand A, Richter-Landsberg C, Leibfritz D. Multinuclear NMR studies on the energy metabolism of glial and neuronal cells. Dev Neurosci 1993; 15 (3-5): 289-298.

35 Schneider P, Weber-Fahr W, Schweinfurth N, Ho YJ, Sartorius A, Spanagel R et al. Central metabolite changes and activation of microglia after peripheral interleukin-2 challenge. Brain Behav Immun 2012; 26(2): 277-283.

36 Spector R. Myo-inositol transport through the blood-brain barrier. Neurochem Res 1988; 13(8): 785-787.

37 Avison MJ, Nath A, Greene-Avison R, Schmitt FA, Bales RA, Ethisham A et al. Inflammatory changes and breakdown of microvascular integrity in early human immunodeficiency virus dementia. J Neurovirol 2004; 10(4): 223-232.

c) (1) $\Theta$ This work is licensed under a Creative Commons Attributioncc) NonCommercial-NoDerivs 4.0 International License. The images or other third party material in this article are included in the article's Creative Commons license, unless indicated otherwise in the credit line; if the material is not included under the Creative Commons license, users will need to obtain permission from the license holder to reproduce the material. To view a copy of this license, visit http:// creativecommons.org/licenses/by-nc-nd/4.0/ 